\title{
Molybdenum disulfide grafted titania nanotube arrays as high capacity retention anode material for lithium ion batteries
}

\author{
Tauseef Anwar ${ }^{1} \cdot$ Li Wang ${ }^{1} \cdot$ Rizwan Ur Rehman Sagar $^{3} \cdot$ Farhat Nosheen $^{4}$. \\ Khurram Shehzad $^{5}$. Naveed Hussain ${ }^{1}$ Liang Tongxiang ${ }^{2,6}$
}

Received: 7 December 2016/Accepted: 15 December 2016/Published online: 30 December 2016

(c) The Author(s) 2016. This article is published with open access at Springerlink.com

\begin{abstract}
Titania nanotube arrays (TNAs) were grown by anodic oxidation method, and molybdenum disulfide $\left(\mathrm{MoS}_{2}\right)$ grafted TNAs have been synthesized via one-step hydrothermal process. The $\mathrm{MoS}_{2}$ grafted TNAs $\left(\mathrm{MoS}_{2} /\right.$ TNAs) when employed as an anode material in lithium ion battery, exhibited excellent areal specific capacity $\left(\sim 430 \mu \mathrm{Ah} \mathrm{cm}^{-2}\right)$ at current density of $50 \mu \mathrm{A} \mathrm{cm} \mathrm{cm}^{-2}$, which is $33 \%$ higher as compared to the pure anatase TNAs and $55 \%$ higher as compared to $\mathrm{MoS}_{2}$. Moreover, the capacity loss per cycle of $\mathrm{MoS}_{2} / \mathrm{TNAs}(\sim 0.21 \%)$ was
\end{abstract}

Electronic supplementary material The online version of this article (doi:10.1007/s13204-016-0543-x) contains supplementary material, which is available to authorized users.

Liang Tongxiang

txliang@tsinghua.edu.cn

1 Beijing Key Lab of Fine Ceramics, Institute of Nuclear and New Energy Technology, Tsinghua University,

Beijing 100084, People's Republic of China

2 State Key Lab of New Ceramic and Fine Processing, Tsinghua University, Beijing 100084,

People's Republic of China

3 Nanshan District Key Lab for Biopolymers and Safety Evaluation, College of Materials Science and Engineering, Shenzhen University, Shenzhen 518060,

People's Republic of China

4 Sulaiman Bin-Abdullah Aba Al-Khail-Centre of Interdisciplinary Research in Basic Sciences (SA-CIRBS), International Islamic University, Islamabad, Pakistan

5 Department of Information Technology and Electronics, Zhejiang University, Hangzhou, People's Republic of China

6 School of Materials Science and Engineering, Jiangxi University of Science and Technology, Ganzhou 100084, Jiangxi, People's Republic of China significantly lower than anatase TNAs $(\sim 1.47 \%)$, suggesting an increase of capacity retention.

Keywords Molybdenum disulfide - Titanium dioxide nanotube arrays $\cdot$ Anode material $\cdot$ Lithium-ion batteries

\section{Introduction}

Lithium-ion batteries (LIBs) are not only attractive practical renewable energy storage devices for high-energy systems such as electrical vehicles, smart grids, etc., (Lu et al. 2013; Peterson et al. 2010; Thackeray et al. 2012) but they also fulfil the need of low energy gadgets such as PC memory, medical implants etc. (Armand and Tarascon 2008; Hu et al. 2010; Kyeremateng 2014). Anode materials of LIBs have a significant effect on the overall performance and efficiency of LIBs (Shehzad et al. 2016; Sagar et al. 2016). However, anode materials for LIBs currently suffer from disadvantages such as, slow ionic diffusion, weak electron transportation, and high interface resistance, which consequently limits the performance of LIBs (Thackeray et al. 2012).

Titanium dioxide $\left(\mathrm{TiO}_{2}\right)$ is one of the attractive anode materials for LIBs due to its cost-effectiveness, chemical stability, and non-toxic nature. Various kinds of low dimensional $\mathrm{TiO}_{2}$ such as nanotubes (Armstrong et al. 2006; Qiu et al. 2010), nanowires (Cao et al. 2010), nanorods (Liu et al. 2012), and nanoparticles (Ren et al. 2012) etc., have been employed as anode for LIBs. Amongst these nanostructures of $\mathrm{TiO}_{2}$ (Armstrong et al. 2006; Qiu et al. 2010; Cao et al. 2010; Liu et al. 2012; Ren et al. 2012; Wang et al. 2011), titanium dioxide nanotube arrays (TNAs) (Guo et al. 2012; Anwar et al. 2015; Tauseef Anwar et al. 2016) are more advantageous owe to higher specific surface area, porosity, and vertical alignment. The TNAs not only provide 
the short lithium ion diffusion path but also accommodate the volume expansion, as well as easy preparation in large scale and self-standing structure facilitates film fabrication (Wu et al. 2012). However, TNAs have lower areal specific capacity (Anwar et al. 2015) which can be improved by adopting different strategies such as, metal or non-metal element doping (Liu et al. 2008, 2009, 2014), annealing in different atmosphere (Lu et al. 2012), conductive coating (Wang et al. 2015), and by compositing with the higher capacity materials (Anwar et al. 2016).

Molybdenum disulfide $\left(\mathrm{MoS}_{2}\right)$ is an attractive material for the practical applications including hydrogen storage, (Chen et al. 2001; Ye et al. 2006) as catalysts, (Hinnemann et al. 2005; Lukowski et al. 2013) lubricants, (Chhowalla and Amaratunga 2000; Savan et al. 2000) double-layer capacitor (Cao et al. 2013; Soon and Loh 2007) as well as lithiun-ion batteries (Hwang et al. 2011; Stephenson et al. 2014; Feng et al. 2009; Li et al. 2009; Dominko et al. 2002). As an anode for lithium insertion/deinsertion, the volume of $\mathrm{MoS}_{2}$ has no significant expansion due to its unique layered structure and weak inter-layer interaction (Sun et al. 2016). Moreover, voids/dislocations in disordered $\mathrm{MoS}_{2}$ results in a significant increase in lithium capacity $\left(\sim 670 \mathrm{mAh}^{-1}\right)$ as well as overall performance of the LIBs (Shehzad et al. 2016; Hwang et al. 2011; Liu et al. 2014; Zhu et al. 2014; Hu et al. 2016; Cui et al. 2015) Different composite of $\mathrm{MoS}_{2}$ with conductive materials (graphene, carbon nanotubes, etc.) have been synthesised for the use of anodes in LIBs. (Zhao et al. 2016; Cao et al. 2013; Hwang et al. 2014) Since, the assembly of layered materials into variety of morphologies such as, nanoarrays is still in infacny, hence, the making composite of $\mathrm{MoS}_{2}$ with arrays of $\mathrm{TiO}_{2}$ may prove an interesting choice.

In this article, $\mathrm{MoS}_{2}$ grafted TNAs have been prepared as a new hybrid anode material in order to improve LIBs performance. The $\mathrm{MoS}_{2} / \mathrm{TNAs}$ composites were fabricated via hydrothermal method and a high lithium stroage capacity of $430 \mu \mathrm{Ah} \mathrm{cm}{ }^{-2}$ has been observed. The magnitude of areal capacity of $\mathrm{MoS}_{2}$ /TNAs is $\sim 33$ and $\sim 55 \%$ higher as compared to the anatase TNAs and $\mathrm{MoS}_{2}$, respectively. Not only the specific capacity is enhanced but also a new morphology of $\mathrm{MoS}_{2}$ also helped to achieve a higher capacity retension. Better electrochemical performace of $\mathrm{MoS}_{2} / \mathrm{TNAs}$ indicates its utility arising from its novel hybrid structure.

\section{Experimental section}

\section{Synthesis of $\mathrm{MoS}_{2}$ /TNAs}

$\mathrm{MoS}_{2}$ grafted TNAs were synthesized according to the previous literature by using hydrothermal method (Fig. 1) (Anwar et al. 2015, 2016). The Ti-foil with grown TNAs was placed with top surface downward in the Teflon liner wall. The $30 \mathrm{~mL}$ solution of $\left(\mathrm{NH}_{4}\right)_{6} \mathrm{Mo}_{7} \mathrm{O}_{24} \cdot 4 \mathrm{H}_{2} \mathrm{O}(1 \mathrm{mmol})$ and thiourea (H2NCSNH2 $\sim 0.484 \mathrm{~g}$ ) was poured into the autoclaves which was Teflon lined. This sealed autoclave placed in oven for $3 \mathrm{~h}$ at the temperature of $180{ }^{\circ} \mathrm{C}$. The autoclave was cooled down to room temperature. After cleaning samples were dehydrated at $80{ }^{\circ} \mathrm{C}$ for $30 \mathrm{~min}$ in vacuum oven. Annealing of $\mathrm{MoS}_{2}$ deposited TNAs ( $\left.\mathrm{MoS}_{2} / \mathrm{TNAs}\right)$ sample was performed at $400{ }^{\circ} \mathrm{C}$ for $2 \mathrm{~h}$ in argon atmosphere.

\section{Characterization}

The morphology of TNAs and $\mathrm{MoS}_{2}$ /TNAs was characterized by using field emission scanning electron microscopy (FE-SEM LEO 1530). The confirmation of TNAs, $\mathrm{MoS}_{2}$ and $\mathrm{MoS}_{2}$ /TNAs phases was performed by using $\mathrm{Cu} K \alpha$ radiation ( $\lambda=0.15 \mathrm{~nm}$ ) of X-ray powder diffraction (Rigaku D/max). Raman spectroscopy of the anatase TNAs, $\mathrm{MoS}_{2}, \mathrm{MoS}_{2} /$ TNAs was recorded on a HR800 micro-Raman spectrometer (Horiba Jobin-Yvon) using a 633 nm He-Ne laser.

\section{Electrochemical characterization}

The electrochemical properties of $\mathrm{MoS}_{2}$ /TNAs composite were assessed by using Lil $\mathrm{MoS}_{2}$ /TNAs half-cells. The coin cell (2032) was assembled in a glove box filled with argon. $\mathrm{MoS}_{2}$ /TNAs was used as cathode without additives, while lithium foil was used as the anode. The cell was ready for the measurement after inserting a separator of celgard 2300 between anode and cathode. The electrolyte of $1 \mathrm{M} \mathrm{LiPF}_{6}$ was dissolved in 1:1 volumetric ratio mixture of dimethyl carbonate (DMC) and ethylene carbonate (EC). The galvanostatically discharge and charge were conducted between 0.005 and $3 \mathrm{~V}$ ( $\mathrm{vs}$. $\mathrm{Li} / \mathrm{Li}^{+}$) at Land battery test system at room temperature. The electrodes used for comparison (TNAs and $\mathrm{MoS}_{2}$ ) were prepared and characterized at same parameters. The cyclic voltammetry (CV) measurement was recorded using electrochemical workstation (CHI660C, CH Instruments, Shanghai, PRC).

\section{Results and discussion}

The morphology of anatase TNAs and $\mathrm{MoS}_{2}$ /TNAs under SEM indicate the smooth, uniform, and vertically aligned TNAs. The top surface and lateral surface do not have any unwanted nanostructures (Fig. 2a-d). The length and average pore diameter of the TNAs was $\sim 3-5 \mu \mathrm{m}$ and $\sim 80 \mathrm{~nm}$, respectively. The $\mathrm{MoS}_{2}$ was grafted at TNAs by hydrothermal reaction for different time durations (i.e. $0-10 \mathrm{~h}$ ) and found excellent performance of the device at $3 \mathrm{~h}$ as the excessive coating hindered the ions and electrons movement (Anwar et al. 2016). The partially covered top 


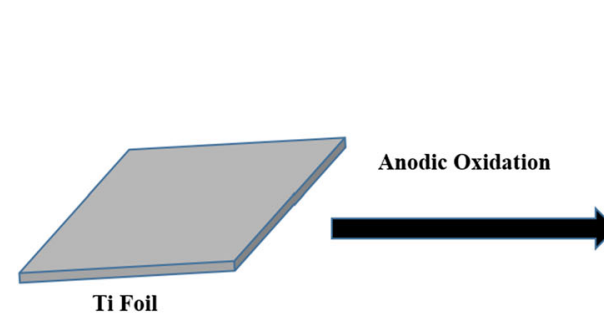

(I)

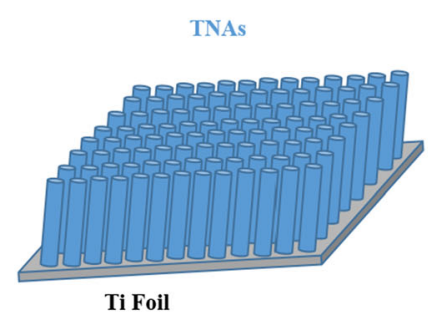

(II)

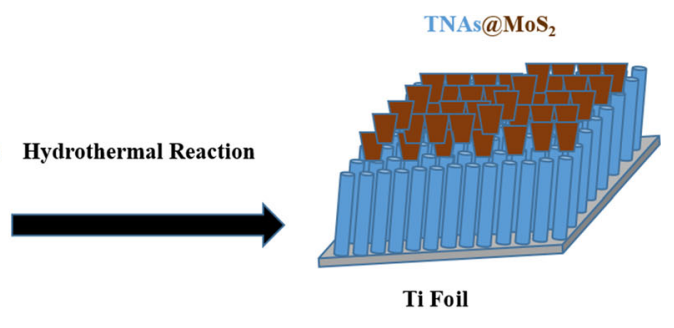

(III)

Fig. 1 The schematic diagram for $\mathrm{MoS}_{2} / \mathrm{TNAs}$ composite fabrication: $I$ Ti foil, $I I$ growth of TNAs at Ti foil, III MoS $/$ TNAs fabrication
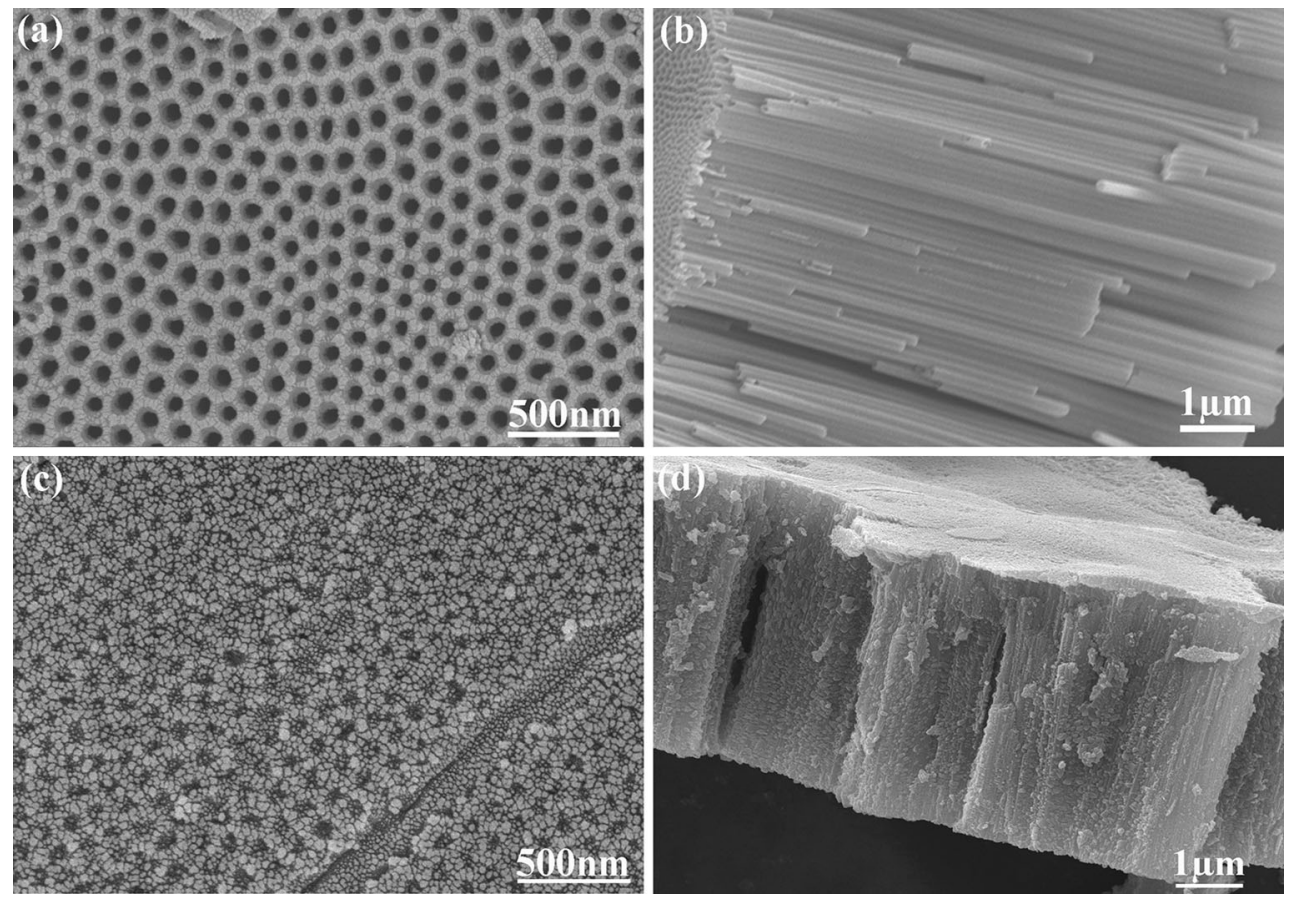

Fig. 2 a TNAs c $\mathrm{MoS}_{2}$ /TNAs and lateral side of b TNAs d $\mathrm{MoS}_{2} / \mathrm{TNAs}$

surface of TNAs with $\mathrm{MoS}_{2}$ can facilitate Li ions and electrons movement through the inner of the nanotubes (Fig. 2c). The $\mathrm{MoS}_{2}$ is also grafted at the lateral sides of TNAs (Fig. 2d), suggesting the filling of TNAs with $\mathrm{MoS}_{2}$. The $\mathrm{MoS}_{2}$ at bare titanium plate by similar method for $10 \mathrm{~h}$ is also shown in Fig. S1. The $\mathrm{MoS}_{2}$ nanoflakes at titanium substrate are $500 \mathrm{~nm}$ long and $10 \mathrm{~nm}$ thick. The dimension of $\mathrm{MoS}_{2}$ increases with the increase in the time.

The XRD peaks given in Fig. 3a indexed well with standard JCPDS No. 44-1294 and JCPDS No. 21-1272 for TNAs and $\mathrm{MoS}_{2}$ /TNAs, respectively. After $\mathrm{MoS}_{2}$ coating the intensities of $\mathrm{TiO}_{2}$ peaks decrease which indicates successful coating ( $\mathrm{Li}$ et al. 2015). The peaks observed at $35^{\circ}, 38.4^{\circ}, 40.1^{\circ}, 53^{\circ}, 62.9^{\circ}, 70.6^{\circ}, 74.1^{\circ}, 76.2^{\circ}$ and $77.4^{\circ}$ represents $\mathrm{Ti}$ foil planes while observed peaks at $14.38^{\circ}$, $29.03^{\circ}, 33.51^{\circ}$ and $62.81^{\circ}$ can be attributed to $\mathrm{MoS}_{2}(002)$, (004), (101), and (101) planes, respectively. Anatase- $\mathrm{TiO}_{2}$ peaks were observed at $25.0^{\circ}(101)$ and $47.9^{\circ}(200)$. The
$\mathrm{MoS}_{2}$ peaks could be observed only in $\mathrm{MoS}_{2}$ /TNAs composite, and anatase $\mathrm{TiO}_{2}$ did not show any $\mathrm{MoS}_{2}$ peak. The XRD results suggest that anatase TNAs and $\mathrm{MoS}_{2} / \mathrm{TNAs}$ are polycrystalline in nature.

The comparison of Raman spectra of anatase TNAs, $\mathrm{MoS}_{2}$, and $\mathrm{MoS}_{2} / \mathrm{TNAs}$ is performed for the investigation of the changes in the electronic structure (Fig. 3b). The intense Raman band at $145 \mathrm{~cm}^{-1}$ in $\mathrm{MoS}_{2} / \mathrm{TNAs}$ corresponds to the main $\mathrm{E}_{\mathrm{g}}$ vibration mode of anatase $\mathrm{TiO}_{2}$. Moreover, the peaks located at $392\left(\mathrm{~B}_{1 \mathrm{~g}}\right), 513\left(\mathrm{~A}_{1 \mathrm{~g}}\right)$, and $634 \mathrm{~cm}^{-1}\left(\mathrm{E}_{\mathrm{g}}\right)$ also confirm the presence of anatase $\mathrm{TiO}_{2}$. In $\mathrm{MoS}_{2}$ spectrum, two broad peaks centered at $397\left(\mathrm{E}_{2 \mathrm{~g}}^{1}\right)$ $\mathrm{cm}^{-1}$ and $406\left(\mathrm{~A}_{1 \mathrm{~g}}\right) \mathrm{cm}^{-1}$ corresponds to the modes of $\mathrm{MoS}_{2}$. The $\mathrm{MoS}_{2}$ peaks are also observed in the Raman spectrum of the $\mathrm{MoS}_{2}$ /TNAs composites, confirming the successful coating of $\mathrm{MoS}_{2}$ species on the anatase TNAs. The blue shift and peak broadening is observed in the mode of $E_{g}, E_{1 g}, A_{1 g}$, and $E_{g}$ in the $\mathrm{MoS}_{2} / T N A s$ as compared to

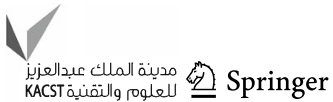




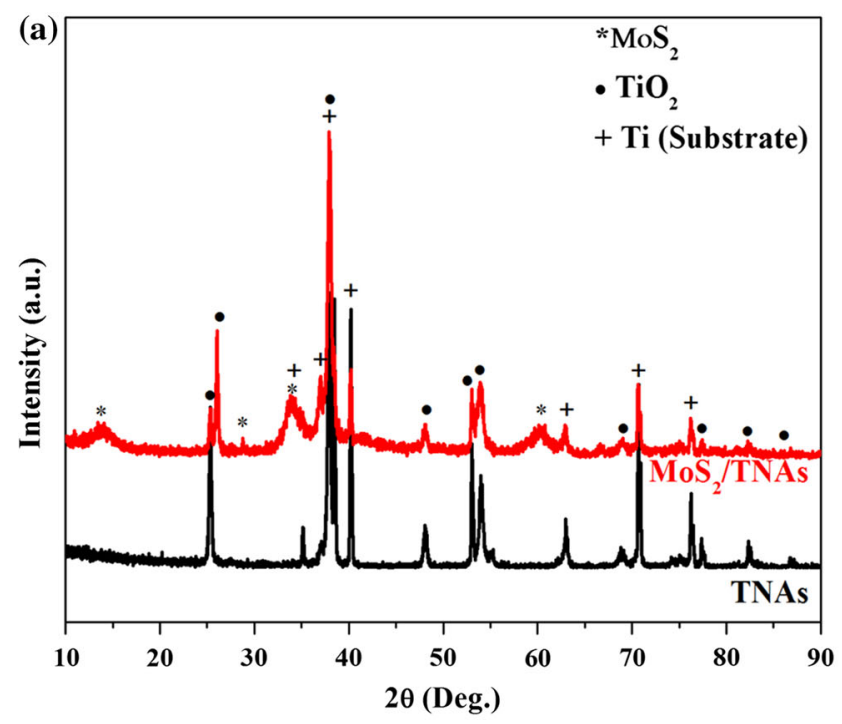

Fig. 3 a XRD and b Raman of TNAs, $\mathrm{MoS}_{2}$ and $\mathrm{MoS}_{2} / \mathrm{TNAs}$

anatase TNAs. The blue shift might be attributed to the induced surface strain by the grafted $\mathrm{MoS}_{2}$ nanoflakes at anatase TNAs surface (Fig. 4).

The cyclic voltammetry (CV) of all prepared electrodes were collected at scan rate of $5 \mathrm{mV} / \mathrm{s}$ in a potential window of $0.005-3 \mathrm{~V}$ vs. $\mathrm{Li}^{2} / \mathrm{Li}^{+}$(Fig. $4 \mathrm{a}-\mathrm{c}$ ). The $\mathrm{CV}$ curve of anatase TNAs showed cathodic peaks at 1.2 and $1.35 \mathrm{~V}$ for 1 st and 2nd cycle, respectively (Fig. 4a). Moreover, anodic peaks at 2.5 and $2.65 \mathrm{~V}$ correspond to the 1 st and 2nd cycle of anatase TNAs, respectively, indicating the Li ion intercalation and de-intercalation potentials of the anatase $\mathrm{TiO}_{2}$. The cathodic peak potentials are higher for 2 nd cycle as compared to 1 st cycle. The shoulder peak was observed at $0.2-1.0 \mathrm{~V}$ for both cycles with major peak, which depicted more lithium storage occurred at nanotubes surfaces and interfaces. The intensity of cathodic shoulder peak of the 2nd cycle is larger as compared to 1 st cycle. Two cathodic/ anodic peaks appeared at $0.6 \mathrm{~V}$ and $1.3 \mathrm{~V}\left(\mathrm{vs} . \mathrm{Li}^{2} \mathrm{Li}^{+}\right)$, respectively in the both cycles of $\mathrm{MoS}_{2}$ anodes (Fig. 4b). The $\mathrm{MoS}_{2}$ /TNAs electrode showed the similar peaks of anatase TNAs cathodic peak and $\mathrm{MoS}_{2}$ cycles behavior, indicating the contribution of TNAs and $\mathrm{MoS}_{2}$ in $\mathrm{MoS}_{2} /$ TNAs anode (Fig. 4c). The whole $\mathrm{Li}^{+}$intercalation and deintercalation reaction can be described as:(Li et al. 2015)

$\mathrm{TiO}_{2}+x \mathrm{Li}^{+}+x \mathrm{e}^{-} \leftrightarrow \mathrm{Li}_{x} \mathrm{TiO}_{2}$

$\mathrm{MoS}_{2}+x \mathrm{Li}^{+}+x \mathrm{e}^{-} \rightarrow \mathrm{Li}_{x} \mathrm{MoS}_{2}$

$\mathrm{Li}_{x} \mathrm{MoS}_{2}+(4-x) \mathrm{Li}^{+}+(4-x) \mathrm{e}^{-} \rightarrow \mathrm{Mo}+2 \mathrm{Li}_{2} \mathrm{~S}$

The first two cycles were discharged/charged at $10 \mu \mathrm{A} \mathrm{cm} \mathrm{cm}^{-2}$ to stabilize the electrochemical properties. The consecutive cycles (3rd-50th) were discharged/charged at current density of $50 \mu \mathrm{A} \mathrm{cm} \mathrm{cm}^{-2}$ in the potential window of $0.005-3 \mathrm{~V}$ (Fig. 4d). In the 3rd discharge, the slope at $1.5-1.2 \mathrm{~V}$

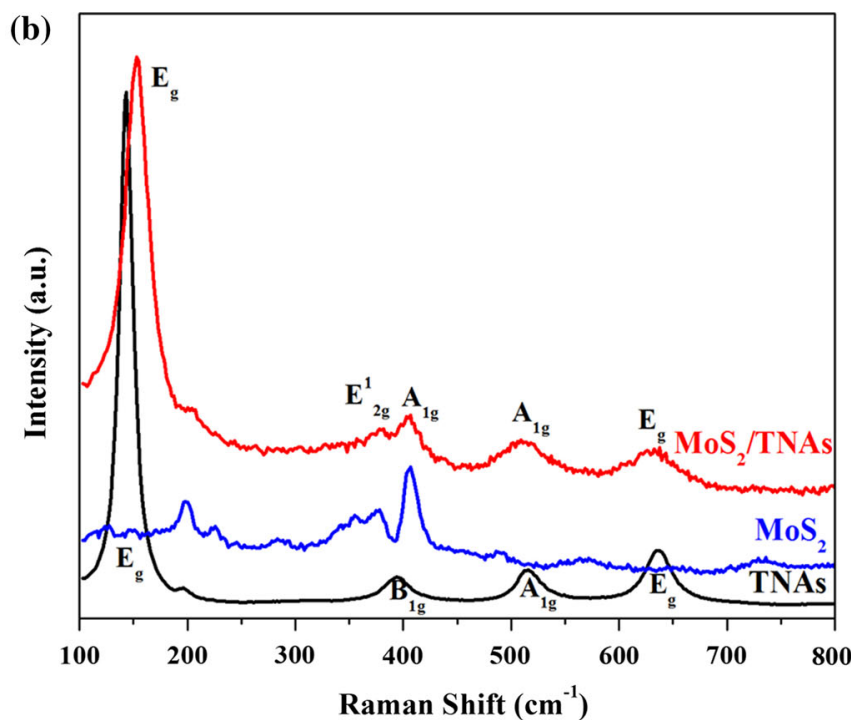

corresponds to the $\mathrm{TiO}_{2}$ lithiation. The slope after $1.0 \mathrm{~V}$ corresponded to the phase transformation from $\mathrm{MoS}_{2}$ to $\mathrm{Li}_{x} \mathrm{MoS}_{2}$ and conversion into $\mathrm{Mo}$ and $\mathrm{Li}_{2} \mathrm{~S}$ (Eq. 3), respectively. The discharge capacity of 3rd cycle is 180,290 , and $430 \mu \mathrm{Ah} \mathrm{cm}^{-2}$ for $\mathrm{MoS}_{2}$, anatase TNAs and $\mathrm{MoS}_{2} / \mathrm{TNAs}$, respectively. The areal specific capacity of $\mathrm{MoS}_{2} /$ TNAs is higher as compared to $\mathrm{MoS}_{2}$ and anatase TNAs. The improved electrochemical performance may be attributed to the synergistic effect of high capacity containing $\mathrm{MoS}_{2}$ and vertically aligned nature of TNAs helps fast $\mathrm{Li}^{+}$kinetics.

To characterize stabilized electrochemical performance, first two discharged/charged were measured at the current density of $10 \mu \mathrm{A} \mathrm{cm}^{-2}$ (Fig. S2 (a) and (b)) while the remaining cycles were measured at $50 \mu \mathrm{A} \mathrm{cm}^{-2}$ (Fig. 5a). The cyclic stability of anatase TNAs reduces continuously from 3 rd to 50 th cycle with $1.47 \%$ capacity loss per cycle, while for $\mathrm{MoS}_{2}$ cyclic performance is very stable from 3rd to 50th cycle with $0.08 \%$ capacity loss per cycle.

In the case of $\mathrm{MoS}_{2} /$ TNAs low capacity fading of TNAs is achieved and the capacity loss per cycle is just $0.21 \%$. So it is an effective way to improve capacity retention. The composite electrode $\mathrm{MoS}_{2}$ /TNAs showed higher discharge/ charge capacity as compared to individual anatase TNAs and $\mathrm{MoS}_{2}$ electrodes. The $\mathrm{MoS}_{2}$ /TNAs nanostructures electrode exhibits a discharge capacity for 3 rd cycle was $430 \mu \mathrm{Ah} \mathrm{cm}^{-2}$ and low capacity fading until 50th cycle $\left(388 \mu \mathrm{Ah} \mathrm{cm}^{-2}\right)$ with capacity loss of $0.21 \%$ per cycle. While the discharge capacity of anatase TNAs and $\mathrm{MoS}_{2}$ electrodes was 84 and $242 \mu \mathrm{Ah} \mathrm{cm}^{-2}$ for 50th cycle, respectively. The efficiency of all electrodes is $100 \%$ during galvanostatic discharge/charge and fluctuates between 101 and 103\% (Fig. 5a).

The rate performance was conducted at current densities of 50, 100, 150, 200, 250 and again $50 \mathrm{~mA} \mathrm{~cm}^{-2}$ for all 

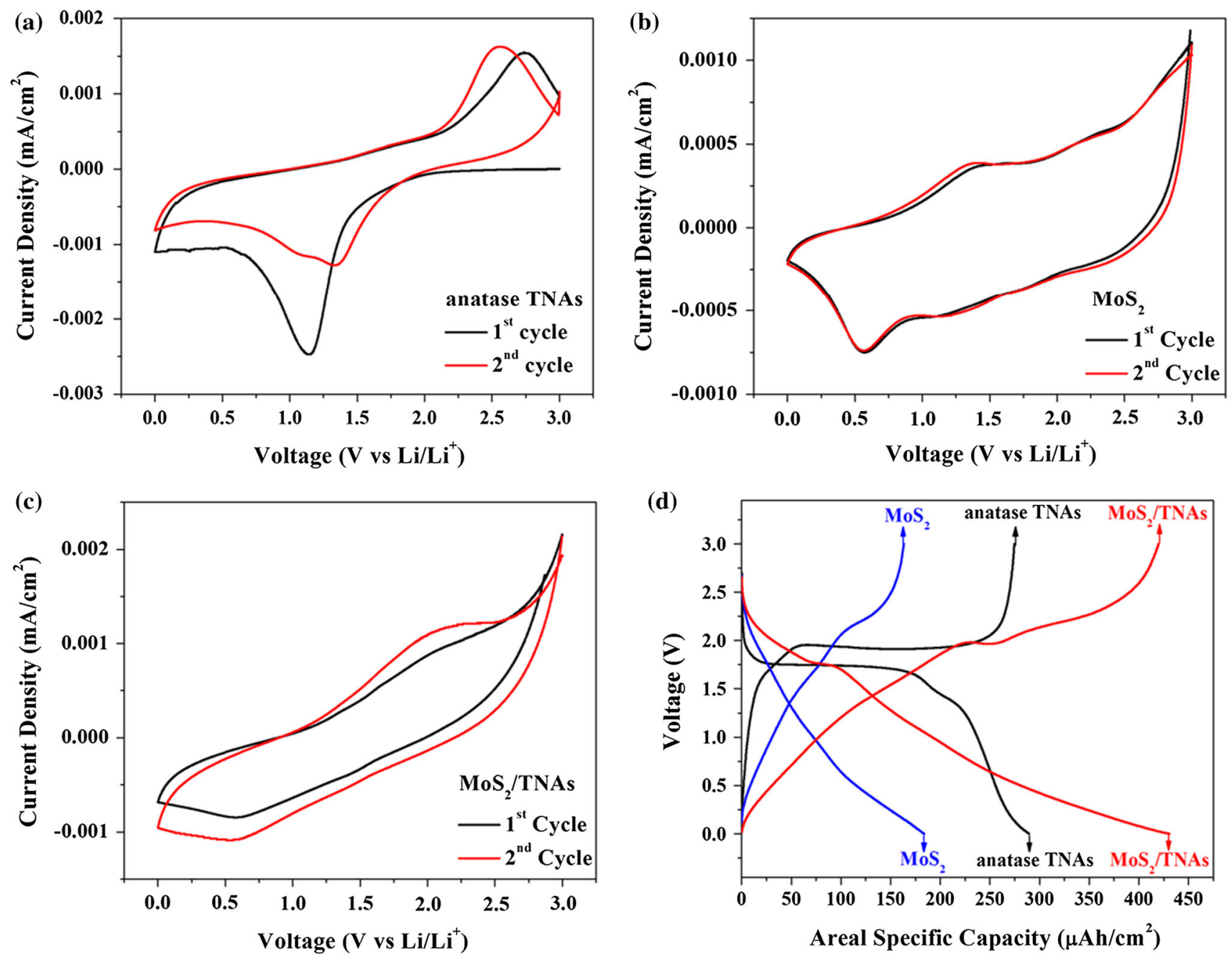

Fig. $4 \mathrm{CV}$ curves for anatase TNAs (a), $\mathrm{MoS}_{2}(\mathbf{b})$ and $\mathrm{MoS}_{2} / \mathrm{TNAs}(\mathbf{c})$. d The 3 rd galvanostatic discharge/charge curve of anatase TNAs, $\mathrm{MoS}_{2}$ and $\mathrm{MoS}_{2} / \mathrm{TNAs}$ at a potential of $0.005-3 \mathrm{~V}$
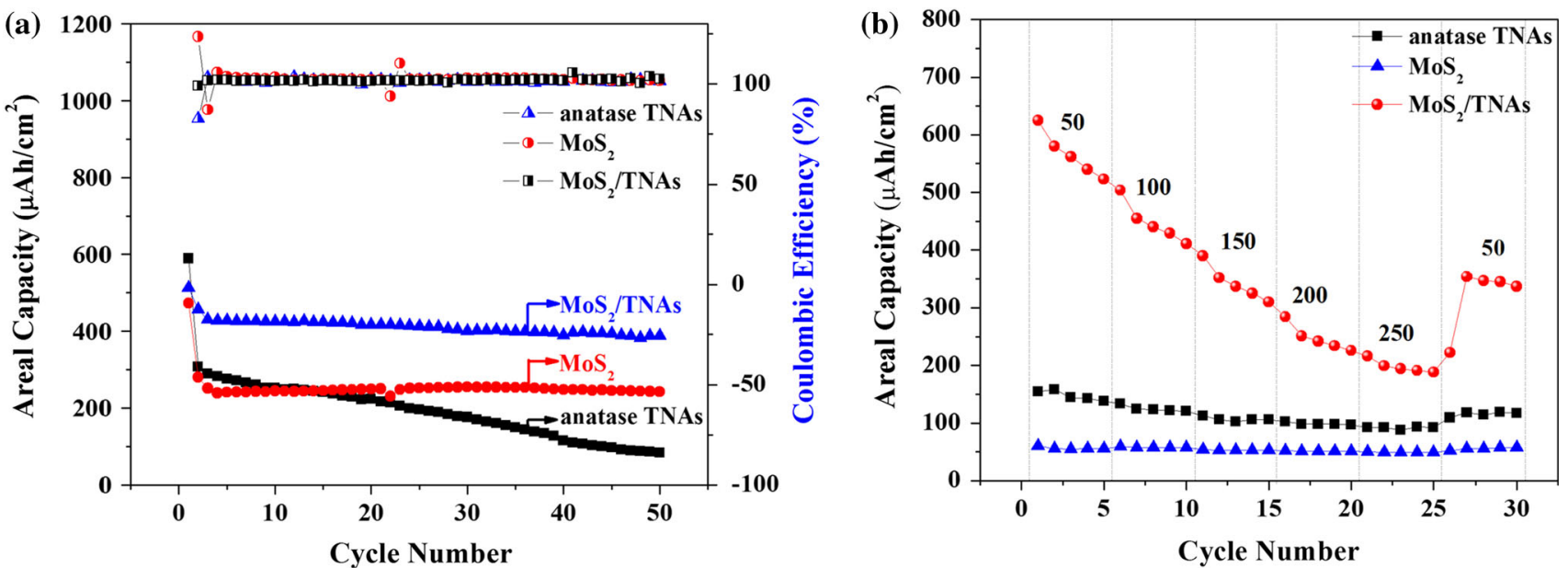

Fig. 5 Cyclic performance and efficiency (a) and rate performance (b) 
electrodes. $\mathrm{MoS}_{2} / \mathrm{TNAs}$ have high rate capability in comparison to anatase TNAs and $\mathrm{MoS}_{2}$. At highest current density when discharge/charge rate switched again at $50 \mathrm{~mA} \mathrm{~cm}{ }^{-2}$, the areal capacity for $\mathrm{MoS}_{2} / \mathrm{TNAs}$ was still more and stable as compared to anatase TNAs and $\mathrm{MoS}_{2}$ (Fig. 5b). So the results depicted that $\mathrm{TiO}_{2}$ and $\mathrm{MoS}_{2}$ incorporate with each other and enhanced the lithium storage rate performance.

The $\mathrm{MoS}_{2} / \mathrm{TNAs}$ can be a practical anode material in LIBs due to the achievement of larger areal capacity as well as high capacity retention. At First, there are no reports about $\mathrm{MoS}_{2}$ grafted TNAs electrode for lithium ion battery and $\mathrm{MoS}_{2}$ grafted TNAs of few micron length with higher specific capacity of $430 \mu \mathrm{Ah} \mathrm{cm}^{-2}$. It might be due to the fabrication process, nanostructures combination, and the synergetic effect of both nanostructured materials (i.e. $\mathrm{MoS}_{2}$ and TNAs). The synergestic effect of $\mathrm{MoS}_{2}$ and TNAs increased the lithium intercalation, which results into a higher capacity and better capacity retention. The hydrothermal fabrication helps to control $\mathrm{MoS}_{2}$ thickness which brings the exciting performance and controllable performance of LIBs.

\section{Conclusion}

The electrochemical properties of $\mathrm{MoS}_{2}$ nanoflakes grafted TNAs were studied for the first time to the best of our knowledge. The specific capacity $\left(\sim 430 \mu \mathrm{Ah} \mathrm{cm}^{-2}\right)$ of $\mathrm{MoS}_{2}$ /TNAs is higher than anatase TNAs $\left(\sim 84 \mu \mathrm{Ah} \mathrm{cm}^{-2}\right)$ and $\operatorname{MoS}_{2}\left(\sim 84\right.$ and $\left.242 \mu \mathrm{Ah} \mathrm{cm}^{-2}\right)$. Anatase TNAs have high capacity fading (i.e. $1.47 \%$ capacity loss/cycle), which was significantly reduced to $0.21 \%$ capacity loss/cycle, owing to the $\mathrm{MoS}_{2}$ nanostructured coating over TNAs. Thus, $\mathrm{MoS}_{2} / \mathrm{TNAs}$ material can be a promising anode material for lithium ion batteries.

Acknowledgements This work is supported by the National Natural Science Foundation of China (Grand No. 21271114); Tsinghua University independent research and development fund (20111080982) and Program for Changjiang Scholars and Innovative Research Team in University (IRT13026).

Open Access This article is distributed under the terms of the Creative Commons Attribution 4.0 International License (http:// creativecommons.org/licenses/by/4.0/), which permits unrestricted use, distribution, and reproduction in any medium, provided you give appropriate credit to the original author(s) and the source, provide a link to the Creative Commons license, and indicate if changes were made.

\section{References}

Anwar T, Wang L, Tongxiang L, He X, Sagar RUR, Shehzad K (2015) Effect of aspect ratio of titanium dioxide nanotube arrays on the performance of lithium ion battery. Int J Electrochem Sci 10(7):6537-6547
Anwar T, Wang L, Jiaoyang L, Chen W, Sagar RUR, Tongxiang L (2016) Lithium storage study on $\mathrm{MoO}_{3}$-grafted $\mathrm{TiO}_{2}$ nanotube arrays. Appl Nanosci 6(8):1-9

Armand M, Tarascon JM (2008) Building better batteries. Nature 451(7179):652-657

Armstrong G, Armstrong AR, Bruce PG, Reale P, Scrosati B (2006) $\mathrm{TiO}_{2}(\mathrm{~B})$ nanowires as an improved anode material for lithiumion batteries containing $\mathrm{LiFePO}_{4}$ or $\mathrm{LiNi} 0.5 \mathrm{Mn} 1.5 \mathrm{O} 4$ cathodes and a polymer electrolyte. Adv Mater 18(19):2597-2600

Cao F-F, Wu X-L, Xin S, Guo Y-G, Wan L-J (2010) Facile synthesis of mesoporous $\mathrm{TiO}_{2}-\mathrm{C}$ nanosphere as an improved anode material for superior high rate $1.5 \mathrm{~V}$ rechargeable $\mathrm{Li}$ ion batteries containing $\mathrm{LiFePO}_{4}-\mathrm{C}$ cathode. J Phys Chem 114(22):10308-10313

Cao L, Yang S, Gao W, Liu Z, Gong Y, Ma L et al (2013a) Direct laser-patterned micro-supercapacitors from paintable $\mathrm{MoS}_{2}$ films. Small 9(17):2905-2910

Cao X, Shi Y, Shi W, Rui X, Yan Q, Kong J et al (2013b) Preparation of $\mathrm{MoS}_{2}$-coated three-dimensional graphene networks for highperformance anode material in lithium-ion batteries. Small 9(20):3433-3438

Chen J, Kuriyama N, Yuan H, Takeshita HT, Sakai T (2001) Electrochemical hydrogen storage in $\mathrm{MoS}_{2}$ nanotubes. J Am Chem Soc 123(47):11813-11814

Chhowalla M, Amaratunga GAJ (2000) Thin films of fullerene-like MoS2 nanoparticles with ultra-low friction and wear. Nature 407(6801):164-167

Cui C, Li X, Hu Z, Xu J, Liu H, Ma J (2015) Growth of $\mathrm{MoS}_{2} @ \mathrm{C}$ nanobowls as a lithium-ion battery anode material. RSC Adv 5(112):92506-92514

Dominko R, Arčon D, Mrzel A, Zorko A, Cevc P, Venturini P et al (2002) Dichalcogenide nanotube electrodes for Li-ion batteries. Adv Mater 14(21):1531-1534

Feng C, Ma J, Li H, Zeng R, Guo Z, Liu H (2009) Synthesis of molybdenum disulfide $\left(\mathrm{MoS}_{2}\right)$ for lithium ion battery applications. Mater Res Bull 44(9):1811-1815

Guo W, Xue X, Wang S, Lin C, Wang ZL (2012) An integrated power pack of dye-sensitized solar cell and Li battery based on double-sided $\mathrm{TiO}_{2}$ nanotube arrays. Nano Lett 12(5):2520-2523

Hinnemann B, Moses PG, Bonde J, Jørgensen KP, Nielsen JH, Horch $S$ et al (2005) Biomimetic hydrogen evolution: $\mathrm{MoS}_{2}$ nanoparticles as catalyst for hydrogen evolution. J Am Chem Soc 127(15):5308-5309

Hu L, Wu H, La Mantia F, Yang Y, Cui Y (2010) Thin, flexible secondary Li-ion paper batteries. ACS Nano 4(10):5843-5848

Hu Z, Liu Q, Sun W, Li W, Tao Z, Chou S-L et al (2016) $\mathrm{MoS}_{2}$ with an intercalation reaction as a long-life anode material for lithium ion batteries. Inorg Chem Front 3(4):532-535

Hwang H, Kim H, Cho J (2011) $\mathrm{MoS}_{2}$ nanoplates consisting of disordered graphene-like layers for high rate lithium battery anode materials. Nano Lett 11(11):4826-4830

Hwang M-J, Kim KM, Ryu K-S (2014) Effects of graphene on $\mathrm{MoO}_{2}-\mathrm{MoS}_{2}$ composite as anode material for lithium-ion batteries. J Electroceram 33(3):239-245

Kyeremateng NA (2014) Self-organised $\mathrm{TiO}_{2}$ nanotubes for 2D or 3D Li-ion microbatteries. Chemelectrochem 1:1442-1466

Li H, Li W, Ma L, Chen W, Wang J (2009) Electrochemical lithiation/delithiation performances of $3 \mathrm{D}$ flowerlike $\mathrm{MoS}_{2}$ powders prepared by ionic liquid assisted hydrothermal route. J Alloys Compd 471(1-2):442-447

Li X, Li W, Li M, Cui P, Chen D, Gengenbach T et al (2015) Glucose-assisted synthesis of the hierarchical $\mathrm{TiO}_{2}$ nanowire@ $\mathrm{MoS}_{2}$ nanosheet nanocomposite and its synergistic lithium storage performance. J Mater Chem A 3(6):2762-2769

Liu D, Xiao P, Zhang Y, Garcia BB, Zhang Q, Guo Q et al (2008) $\mathrm{TiO}_{2}$ nanotube arrays annealed in $\mathrm{N}_{2}$ for efficient lithium-ion intercalation. J Phys Chem C 112(30):11175-11180 
Liu D, Zhang Y, Xiao P, Garcia BB, Zhang Q, Zhou X et al (2009) $\mathrm{TiO}_{2}$ nanotube arrays annealed in $\mathrm{CO}$ exhibiting high performance for lithium ion intercalation. Electrochim Acta 54(27):6816-6820

Liu S, Jia H, Han L, Wang J, Gao P, Xu D et al (2012) Nanosheetconstructed porous $\mathrm{TiO}_{2}-\mathrm{B}$ for advanced lithium ion batteries. Adv Mater 24(24):3201-3204

Liu Y, Zhao Y, Jiao L, Chen J (2014) A graphene-like $\mathrm{MoS}_{2} /$ graphene nanocomposite as a highperformance anode for lithium ion batteries. J Mater Chem A 2(32):13109-13115

Lu Z, Yip C-T, Wang L, Huang H, Zhou L (2012) Hydrogenated $\mathrm{TiO}_{2}$ nanotube arrays as high-rate anodes for lithium-ion microbatteries. Chempluschem 77(11):991-1000

Lu L, Han X, Li J, Hua J, Ouyang M (2013) A review on the key issues for lithium-ion battery management in electric vehicles. J Power Sources 226:272-288

Lü X, Yang W, Quan Z, Lin T, Bai L, Wang L et al (2014) Enhanced electron transport in $\mathrm{Nb}$-Doped $\mathrm{TiO}_{2}$ nanoparticles via pressureinduced phase transitions. J Am Chem Soc 136(1):419-426

Lukowski MA, Daniel AS, Meng F, Forticaux A, Li L, Jin S (2013) Enhanced hydrogen evolution catalysis from chemically exfoliated metallic $\mathrm{MoS}_{2}$ nanosheets. J Am Chem Soc 135(28): 10274-10277

Peterson SB, Apt J, Whitacre JF (2010) Lithium-ion battery cell degradation resulting from realistic vehicle and vehicle-to-grid utilization. J Power Sources 195(8):2385-2392

Qiu Y, Yan K, Yang S, Jin L, Deng H, Li W (2010) Synthesis of sizetunable anatase $\mathrm{TiO}_{2}$ nanospindles and their assembly into anatase@titanium oxynitride/titanium nitride-graphene nanocomposites for rechargeable lithium ion batteries with high cycling performance. ACS Nano 4(11):6515-6526

Ren Y, Liu Z, Pourpoint F, Armstrong AR, Grey CP, Bruce PG (2012) Nanoparticulate $\mathrm{TiO}_{2}(\mathrm{~B})$ : an anode for lithium-ion batteries. Angew Chem Int Ed 51(9):2164-2167

Sagar RUR, Mahmood N, Stadler FJ, Anwar T, Navale ST, Shehzad $\mathrm{K}$ et al (2016) High capacity retention anode material for lithium ion battery. Electrochim Acta 211:156-163

Savan A, Pflüger E, Voumard P, Schröer A, Simmonds M (2000) Modern solid lubrication: recent developments and applications of $\mathrm{MoS}_{2}$. Lubr Sci 12(2):185-203

Shehzad K, Xu Y, Gao C, Duan X (2016) Three-dimensional macrostructures of two-dimensional nanomaterials. Chem Soc Rev 45(20):5541-5588
Soon JM, Loh KP (2007) Electrochemical Double-layer capacitance of $\mathrm{MoS}_{2}$ nanowall films. Electrochem Solid State Lett 10(11):A250-A254

Stephenson T, Li Z, Olsen B, Mitlin D (2014) Lithium ion battery applications of molybdenum disulfide $\left(\mathrm{MoS}_{2}\right)$ nanocomposites. Energy Environ Sci 7(1):209-231

Sun X, Wang Z, Li Z, Fu YQ (2016) Origin of structural transformation in mono- and bi-layered molybdenum disulfide. Sci Rep 6:26666

Tauseef Anwar WL, Hussain N, Chen W, Sagar RUR, Tongxiang L (2016) Effect of annealing atmosphere induced crystallite size changes on the electrochemical properties of $\mathrm{TiO}_{2}$ nanotubes arrays. J Electr Eng 4:43-51

Thackeray MM, Wolverton C, Isaacs ED (2012) Electrical energy storage for transportation-approaching the limits of, and going beyond, lithium-ion batteries. Energy Environ Sci 5(7):7854-7863

Wang J, Zhou Y, Hu Y, O'Hayre R, Shao Z (2011) Facile synthesis of nanocrystalline $\mathrm{TiO}_{2}$ mesoporous microspheres for lithium-ion batteries. J Phys Chem C 115(5):2529-2536

Wang XH, Guan C, Sun LM, Susantyoko RA, Fan HJ, Zhang Q (2015) Highly stable and flexible Li-ion battery anodes based on $\mathrm{TiO}_{2}$ coated 3D carbon nanostructures. J Mater Chem A 3(30):15394-15398

Wu QL, Li J, Deshpande RD, Subramanian N, Rankin SE, Yang F et al (2012) Aligned $\mathrm{TiO}_{2}$ nanotube arrays as durable lithium-ion battery negative electrodes. J Phys Chem C 116(35):18669-18677

Ye L, Wu C, Guo W, Xie Y (2006) $\mathrm{MoS}_{2}$ hierarchical hollow cubic cages assembled by bilayers: one-step synthesis and their electrochemical hydrogen storage properties. Chem Commun 45:4738-4740

Zhao B, Wang Z, Gao Y, Chen L, Lu M, Jiao Z et al (2016) Hydrothermal synthesis of layer-controlled $\mathrm{MoS}_{2} /$ graphene composite aerogels for lithium-ion battery anode materials. Appl Surf Sci 390:209-215

Zhu C, Mu X, van Aken PA, Yu Y, Maier J (2014) Single-layered ultrasmall nanoplates of $\mathrm{MoS}_{2}$ embedded in carbon nanofibers with excellent electrochemical performance for lithium and sodium storage. Angew Chem Int Ed 53(8):2152-2156 